\title{
De zona olvidada a plataforma de expansión. Centroamérica en las representaciones cartográficas y proyectos navales ingleses $(1680-1742)^{*} /$
}

\author{
From Forgotten Area to Platform of Expansion. \\ Central America in the Cartographic Representations \\ and English Naval Projects (1680-1742)
}

Guadalupe Pinzón Ríos

ORCID iD: http://orcid.org/0000-0003-1075-9371

Instituto de Investigaciones Históricas, UNAM

\begin{abstract}
El objetivo de este artículo es analizar la manera en que los ingleses proyectaron sus intereses sobre Centroamérica y la vislumbraron como una plataforma que les permitiría extender sus actividades navales del Atlántico al Pacífico. Esas intenciones las mostraron en sus diarios de viaje y mapas. Estos materiales se convirtieron en instrumentos de poder a través de los cuales los ingleses intentaron justificar sus avances y trataron de hacerlos permanentes. Vale la pena analizar este proceso pues posteriormente volvieron a usar esos métodos en otras regiones.

PALABRAS Clave: Centroamérica; Mapas; Navegación; Ingleses; Expediciones; Diarios.

The aim of this article is to analyze how the English became interested in Central America and planned to use it as a platform to extend their naval activities from the Atlantic to the Pacific. They revealed their intentions in their accounts of their voyages and in their maps. Those accounts and maps became instruments of power to justify their advances, and by means of them, they tried to make their presence permanent. Is important to analyze this process because the English used this method again in other areas.
\end{abstract}

Keywords: Central America; Maps; Navigation; English; Expeditions; Accounts.

Copyright: (C) 2018 CSIC. Este es un artículo de acceso abierto distribuido bajo los términos de la licencia de uso y distribución Creative Commons Reconocimiento 4.0 Internacional (CC BY 4.0).

* Este trabajo se realizó en el marco de la estancia sabática realizada en 2016-2017 gracias a una beca otorgada por el Programa de Apoyo para la Superación del Personal Académico (PASPA) 2016 de la Dirección General de Asuntos del Personal Académico (DGAPA) de la UNAM, así como del Apoyo para Estancias Sabáticas vinculadas a la consolidación de grupos de investigación y/o el fortalecimiento del Posgrado Nacional en el marco de la convocatoria 2016 del CONACYT. Agradezco al Dr. Francisco Roque de Oliveira por ser mi anfitrión durante esa estancia en el Centro de Estudos Geográficos (CEG), Instituto de Geografia e Ordenamento do Território (IGOT), Universidade de Lisboa. 
A raíz de que los ingleses ocuparan Jamaica (1655) sus incursiones sobre las costas y asentamientos del Caribe se incrementaron paulatinamente. Para frenar esos avances la Corona española acordó la firma del Tratado de Madrid (1670) con el cual aceptaba la posesión de Inglaterra sobre Jamaica a cambio de que se frenaran las agresiones sobre asentamientos hispanos. Mientras se llevaba a cabo dicha negociación, las huestes inglesas continuaron sus ataques y uno de los más relevantes fue el comandado por Henry Morgan, quien avanzó y rindió Portobelo (1670) y poco después Panamá (1671). Esta ocupación se prolongó durante tres semanas y posteriormente, al llegar las noticias de la reciente paz firmada, ambas plazas fueron devueltas. Pero el hecho de que este avance permitiera a los ingleses organizar saqueos diversos a lo largo del Pacífico despertó el interés de otros navegantes para llevar a cabo nuevas correrías por ese océano, y fue en la década de 1680 cuando las reiniciaron. ${ }^{1}$ Pronto también consideraron la posibilidad de contar con asentamientos en territorio continental que les permitieran alcanzar e incluso hacer regular su presencia en aquellas costas, por lo que la región centroamericana comenzó a formar parte de sus nuevos objetivos.

La intención de este texto es analizar la manera en que los ingleses proyectaron sus intereses sobre Centroamérica y la vislumbraron como una plataforma que les permitiría extender sus actividades del Mar del Norte al Mar del Sur. Esos proyectos los dejaron ver a partir de los registros que hicieron de la zona en sus diarios de viaje y mapas. Se parte de la idea de que Centroamérica, más allá de poder ser usada como zona de tránsito, se convirtió en un deseado botín por sí misma. ${ }^{2}$ Asegurar una posición en ese lugar no únicamente se relacionó con el interés de llevar a cabo capturas de naves, mercancías o metales, sino que esto permitiría la continuidad de las avanzadas inglesas por el Mar del Sur pues se brindaría un punto de escala donde sus navegantes podrían recibir ayuda u obtener materiales necesarios como eran maderas, alimentos o agua. Pero también fundar un establecimiento justificaría la presencia de los ingleses en la zona y daría cierta legalidad a sus incursiones por el Pacífico. Para lograrlo, la ocupación de Centroamérica

1 La ocupación de Jamaica y los posteriores avances ingleses han sido ampliamente estudiados. De forma general el tema puede verse, entre otros, en Jármy, 1983; Haring, 2003; Lynch, 1989; García de León, 2004. Respecto a las navegaciones inglesas por el Pacífico pueden verse los trabajos de Gerhard, 2003, y Spate, 1983.

2 Hay que señalar que para fines prácticos en este trabajo se hará referencia a la región y no tanto a sus divisiones administrativas pues estas son poco referidas en las fuentes inglesas consultadas. 
comenzó siendo simbólica a partir de bautismos cartográficos ${ }^{3}$ de algunos puntos, así como de narraciones donde se mencionaban alianzas que se decía establecer con los pueblos de indios no sujetos a la administración española. Al respecto, Ángela Pérez Mejía explica cómo Centroamérica se convirtió en una zona intermedia entre los intereses coloniales europeos y que en el caso de los ingleses, durante el siglo XVII, la ilegalidad fue una forma de apropiarse de ella pues planearon ocupar espacios geográficos en los límites de las divisiones coloniales; este proceso obliga a repensar en las representaciones geoculturales de los intereses europeos que generaron los encuentros coloniales. ${ }^{4}$ En el caso centroamericano, una buena forma de lograr lo anterior es a través de las narraciones y registros cartográficos que los ingleses hicieron de dicha zona. Según explica Mariselle Meléndez, las narraciones de viaje y la cartografía son herramientas para analizar cómo los lugares fueron construidos a partir de discursos retóricos con los que se intentó persuadir, convencer y en ocasiones hasta imponer aspectos culturales, políticos o religiosos. ${ }^{5}$ Por su parte, Karl Schlögel explica cómo los mapas son instrumentos de poder con su propia retórica o narrativa cartográfica, lo cual permite usarlos como fuente de información pues en ellos pueden verse procesos como guerras, asedios, huidas, dominios imperiales, valores culturales, entre otros muchos aspectos. ${ }^{6}$ Por ello, como recuerda John Harley, los mapas como objetos culturales dejan ver las realidades físicas y sociales de su época y por esa razón deben ser leídos en el contexto en el que fueron elaborados. ${ }^{7}$ En el caso de las descripciones, narraciones y representaciones hechas sobre Centroamérica, estos materiales formaron parte de las proyecciones y justificaciones que los ingleses preparaban al dirigir sus avanzadas al Mar del Sur a través de dicha zona.

Cabe señalar que no se intenta hacer una relación de las travesías que incursionaron en el Pacífico a través de la región centroamericana, sino más bien analizar algunas en las que se hicieron representaciones de ella. Esto cobra sentido si se asume que el espacio no debe ser considerado un simple escenario donde se desarrollaron acontecimientos humanos, sino que ha

3 Según explica John Elliott el bautismo cartográfico es la ocupación simbólica que se hizo de un espacio y cuyo registro pronto fue llevado a los mapas; lo menciona sobre todo para el caso del Caribe. Elliott, 2006, 67-70.

4 Pérez Mejía, 2002, 185

5 Meléndez, 2009, 175.

6 Schlögel, 2007, 16-17.

7 Harley, 2005, 59-78 («Textos y contextos en la interpretación de los primeros mapas»). 
formado parte de esos acontecimientos y por ello también merece ser tema de reflexión. ${ }^{8}$

Los proyectos ingleses sobre Centroamérica en especial pueden apreciarse desde 1680, cuando reiniciaron las expediciones de bucaneros rumbo al Pacífico, y hasta 1742, cuando tras el viaje de George Anson comenzaron a reestructurarse los planes navales de Inglaterra sobre ese océano. Si bien en esos cambios la región centroamericana no quedó fuera de los proyectos navales ingleses, se le dejó de tener como única posibilidad de alcanzar al Mar del Sur y tentativamente se consideraron nuevas opciones.

\section{Primeras proyecciones de avance}

Desde el siglo XVI los cronistas españoles comenzaron a ser leídos por los ingleses y pronto se despertó el interés de participar en las avanzadas hacia el Nuevo Mundo. Fue en el marco del ascenso de Isabel I como reina de Inglaterra, y del distanciamiento que se generó con la Corona española, cuando se iniciaron algunas acciones. En ese contexto el Caribe se mostró como territorio apetecible en el que piratas y corsarios de diversas potencias europeas realizaron ataques al comercio y a las poblaciones coloniales hispanas; pronto esos avances incluyeron la fundación de sus propios asentamientos. Si bien las Antillas menores comenzaron a ser ocupadas por los enemigos de España, en el caso inglés también se llegó a considerar que la conquista de Santo Domingo o Cuba aseguraría bases para lanzar ataques a los virreinatos de Nueva España y Perú, pero para lograrlo había que conocer dichos territorios. Ante ese escenario las informaciones sobre América fueron muy valoradas. ${ }^{9}$ Entre las lecturas que más se popularizaron estuvieron los textos de Fray Bartolomé de las Casas; sus descripciones sobre Guatemala y Honduras fueron usadas como propaganda anti española pues se difundió la visión de que se cometían diversas atrocidades sobre los indígenas. ${ }^{10} \mathrm{~A}$ este tipo de textos pronto se sumaron las compilaciones que Richard Hakluyt hizo de diversas navegaciones inglesas. Su obra más conocida, Principal Navigations, fue publicada en la década de 1580 y en ella se incluyeron travesías como las de Francis Drake y Thomas Cavendish, quienes atacaron varios asentamientos hispanos (algunos en el Caribe y en

8 Martínez, 2009, 35-39.

9 Valencia, 2015, 78-80.

10 Ibidem, 83-84. 
la región centroamericana) e incluso navegaron por el Mar del Sur. ${ }^{11}$ Por otro lado, había personajes interesados en llevar a cabo avances por Centroamérica como se vio con el caso de Walter Raleight, quien desde 1592 había intentado encontrar el legendario Dorado en la selva del Darién. ${ }^{12}$

Hacia el siglo XVII se concretó un proyecto más oficial. En 1655 Oliver Cromwell ordenó una expedición contra las posesiones hispánicas que minara su comercio con la metrópoli; aunque el ataque se dirigió a Santo Domingo, la defensa del lugar hizo que los ingleses se retiraran y tomaran rumbo a una plaza menos protegida, lo cual derivó en la captura de Jamaica. Tras este hecho la presencia inglesa se hizo más permanente en el Caribe y se incrementaron sus actividades de saqueo y contrabando en aquellos litorales; el punto culminante fue la captura de Portobelo y Panamá a manos de Henry Morgan. Aunque en 1670, con la Paz de Madrid, se aceptó que Jamaica oficialmente sería posesión de los ingleses a cambio de que estos redujeran sus contrabandos y pillajes, esto en realidad poco se cumplió y, por el contrario, dichos navegantes paulatinamente extendieron sus intereses y actividades a territorio continental. En realidad esto se había logrado por la poca presencia hispana en la zona debido a la decadencia y abandono que desde el siglo XVI sufrieron los puertos atlánticos de Santo Tomás, Trujillo y Caballos tras diversos ataques piratas; incluso los contactos de Guatemala con la metrópoli se hacían a través de Veracruz o Portobelo, dejando poco vigiladas las costas del Mar del Norte. ${ }^{13}$ Aunado a lo anterior, y aprovechando la poca presencia hispana, en las zonas costeras de Campeche, Honduras, Nicaragua y Costa Rica los ingleses fueron estableciendo y multiplicando campamentos de cortadores de palo de tinte. ${ }^{14}$ Podría pensarse que para el siglo XVII, en la mente de los ingleses el Caribe continental representaba una puerta de acceso para los virreinatos americanos por estar escasamente protegida y controlada por los españoles. ${ }^{15}$ Junto a ello, la captura de Panamá había mostrado que por esa región podrían extenderse sus avances hacia el Mar del Sur así como sus correrías para obtener botines diversos. ${ }^{16}$

11 Ibidem, 85. Estas travesías y la forma en que se hablaba de ellas en la obra de Hakluyt pueden verse con detalle en Ita, 2001.

12 Valencia, 2015, 89.

13 Sobre los ataques y abandono de las costas centroamericanas de cara al Atlántico: MacLeod, 1980, cap. XIV. Pérez Brignoli, 1993, 44-45. Pinto, 1993, 128-129.

14 Lynch, 1989, 231. García de León, 2004, 75-76. Pérez Brignoli, 1986, 48-52.

15 Valencia, 2015, 92.

16 Esto llegó a ser mencionado en la obra de Exquemelin, 2002 [1678], 246-284. 
En 1680 varios ingleses de Jamaica participaron en nuevas expediciones y sus avances se dieron tanto por el istmo de Panamá como por Tierra de Fuego. Estos hombres, referidos genéricamente como bucaneros, ${ }^{17}$ retomaron las prácticas de «los Hermanos de la Costa» del Caribe (y del mismo Morgan) de no construir naves, sino que debían capturarlas. Como sus acciones se realizarían en el Pacífico, algunos ingleses decidieron avanzar por tierra hasta esas costas y ahí capturar las embarcaciones a utilizar. Hay que señalar que se tenía la certeza de que eso se lograría ya que las huestes de Morgan lo hicieron previamente, y eso había evidenciado que en las costas del Mar del Sur las navegaciones interamericanas se practicaban con cierta regularidad.

Sobre este punto hay que recordar que los principales intercambios marítimos a lo largo del Pacífico estaban a cargo de naves peruanas, las cuales generalmente viajaban a Panamá para llevar plata y recoger los cargamentos que los galeones de Tierra Firme llevaban a Portobelo. Durante su tránsito solían hacer escala en Realejo y Sonsonate para proveerse de jarcias, alquitrán y brea necesarios en los astilleros de Guayaquil y El Callao. Para 1685 también se autorizó a esas naves que cargaran vino, vinagre y frutos secos debido a que estos no llegaban fácilmente a Guatemala desde el Atlántico. Por otro lado, algunas embarcaciones de Realejo y Sonsonate viajaban a Acapulco con pertrechos navales destinados para hacer reparaciones a los galeones de Manila que anualmente llegaba a ese puerto y a cambio de esos pertrechos se obtenían productos novohispanos y plata. Aunado a lo anterior, eran regulares los contrabandos, entre los que destacaban los de cacao guayaquileño, géneros asiáticos y plata, entre otros. ${ }^{18}$

Podría decirse que mientras que las costas atlánticas de Centroamérica habían sido parcialmente abandonadas desde el siglo XVI, las que estaban frente al Pacífico tenían múltiples actividades marítimas a nivel interamericano (legal e ilegal) y la zona era un punto de encuentro entre Nueva España y Perú. No obstante, administrativamente esta era periférica para ambos virreinatos, por lo que la presencia de las autoridades reales fue menor que en

17 Según explica Martha de Jármy, esos bucaneros no eran los mismos que en el siglo XVI se dedicaban a preparar carne ahumada o bucán, sino que era la forma de referirse a los navegantes no asentados en las islas y más ligados a la piratería que continuaron con sus correrías aun después de que se ordenó que no se practicara más esa actividad. Jármy, 1983, 130-134.

18 Sobre los tratos interamericanos ver Pérez Herrero, 1992, 179-182. Específicamente sobre el cacao guayaquileño ver Hernández, 2008. Sobre la forma en la que las navegaciones peruanas y novohispanas convergían en las costas guatemaltecas ver Pérez Brignoli, 1993, 41-46. 
las regiones centrales. ${ }^{19}$ Lo anterior hace comprensible que se tratara de un espacio poco vigilado y con mínima presencia hispana. Es posible que en las incursiones previas, así como tras los avances de los cortadores de palo de tinte, los ingleses hubieran percibido esa situación, la cual aprovecharon para llevar a cabo sus nuevos planes. Una de las regiones menos protegida era la del Darién y fue en ella donde se llevó a cabo la expedición de 1680.

\section{Darién: puerta de entrada al Mar del Sur}

La expedición que en 1680 cruzó el Darién alcanzó las costas del Pacífico y ahí sus integrantes lograron capturar cinco embarcaciones. La mayor, llamada Nuestra Señora de la Trinidad (de 400 toneladas), fue rebautizada como Trinity y se convirtió en la nave insignia de la armadilla; su mando se encargó a Richard Sawkins. El resto de las naves fueron capitaneadas por John Coxon, Peter Harris, Edmund Cook y Bartholomew Sharp. La armadilla inicio viaje y alcanzó las costas de Panamá, pero en Pueblo Nuevo fueron rechazados por las fuerzas locales y en la trifulca Sawkins murió. Esto llevó a que las huestes se separaran y tomaran rutas distintas. ${ }^{20}$

La expedición que se dirigió al sur iba comandada por Sharp, quien planeó viajar a las costas de Perú y Chile. Antes de lograrlo, tuvieron que hacer escala para buscar pertrechos y alimentos. Fue en ese tránsito cuando, frente a las costas de Guayaquil, lograron capturar al navío Nuestra Señora del Rosario en el cual se llevaba un libro de mapas españoles en el que se mostraban las costas desde la California hasta el Estrecho de Magallanes. ${ }^{21}$ El libro fue llevado a Londres y entregado al rey Carlos II, quien lo dirigió al cartógrafo William Hack para que lo tradujera, lo cual derivó en la publicación de un atlas. ${ }^{22}$ Cabe señalar que uno de los participantes de la expedición de Sharp, Basil Ringrose, copió los mapas peruanos e hizo

19 Pinzón, 2016.

20 Gerhard, 2003, 147-148. Pinzón, 2015.

21 Howse y Thrower, 1992, 2-22. Gerhard, 2003, 146-153. Cabe señalar que no es probable que se tratase de un libro sino más bien de un derrotero (integrado por un conjunto de mapas) en el que se representaron las costas del Pacífico. Esto se asume debido a la existencia de otros derroteros peruanos. Uno de ellos es el «Derrotero General del Mar del Sur», manuscrito fechado en Panamá en 1669, que se resguarda en la Huntington Library. Un ejemplo más tardío (fechado en Lima en 1764) se encuentra en el Museo Naval de Madrid, pero puede verse en Pinzón, 2008.

22 De este atlas existen varias versiones pues se reeditó con adecuaciones que se hicieron conforme llegaban nuevos informes de las navegaciones realizadas por el Pacífico; la versión que se usa para este trabajo es la de 1698, que se resguarda en la John Carter Brown Library (Hack, 1698). Sobre el tema ver Pinzón, 2015. 
diversas anotaciones y traducciones de los lugares señalados en ellos, notas que fueron retomadas por Hack y vertidas en su atlas. ${ }^{23}$

Es importante recordar que el atlas de Hack se elaboró en el marco de las transformaciones navales y cartográficas que se gestaban en Inglaterra, reino que tras el incremento y diversificación de sus contactos marítimos requirió de nuevos mapas sobre las regiones por donde transitaban sus navegantes, así como de aquellas a las que se dirigían sus intereses. La elaboración de esos mapas recayó en cartógrafos particulares, muchos de los cuales se establecieron a lo largo del Támesis y por ello fueron conocidos como miembros de la Thames School. Ellos se dieron a la tarea de diseñar cartas náuticas que incluyeran los registros que los ingleses hacían durante sus travesías. ${ }^{24} \mathrm{Y}$ en ese contexto los mapas capturados frente a Guayaquil representaron una importante fuente de información sobre el Pacífico. Por ello en el atlas de Hack (y previamente en las notas de Ringrose) se incluyeron representaciones de las costas americanas con informaciones estratégicas como perfiles costeros, bajos, bahías, ríos o poblaciones. Y en esas representaciones la región de Centroamérica fue detalladamente señalada. Por ejemplo, Ringrose dijo que el Golfo Dulce era muy buen puerto (mejor que el de Nicoya) pues era seguro de vientos y de españoles, ya que estos poca presencia tenían en el lugar; además, los indios de la zona eran amigables y ahí se podían obtener maderas y agua. Al parecer, se vio plausible usar la zona con cierta regularidad, por lo que se tomó posesión simbólica de ella. En la narración de Ringrose se indicó que Sharp había bautizado esa bahía como King Charles y plantó una bandera para legitimar esta acción. ${ }^{25}$ En el atlas de Hack se retomó esta narración y el mapa del Golfo Dulce aparece señalado como King Charles's Harbour, además de que en la leyenda se indicó la toma hecha por Sharp «por la razón [de que] él elevó tiendas en la costa y esos indios se acercaron y fueron a bordo y comerciaron con los ingleses y ahí también centraron sus naves y tomaron provisiones, madera y agua» (ver figura 1$){ }^{26}$

23 Ringrose también elaboró un diario de viaje donde narraba la expedición de Sharp, pero su texto no fue publicado en su momento debido a la muerte del bucanero. No obstante, una parte de él fue publicado en una reedición de 1685 del trabajo de Alexandre O. Exquemelin. Ver Howse y Thrower, 1992, 38-40.

24 Tarea que comenzaron a hacer sobre todo para separarse de la cartografía neerlandesa que acostumbraban utilizar. Ver Maeer, 2006, 6-10. Suárez, 2004, 78-88.

25 Tomado de Howse y Thrower, 1992, 110-111. Como antes se indicó, el manuscrito de Ringrose no fue publicado en su momento (1682), y fueron estos autores los que llevaron a cabo esa labor y por eso se recurre a su trabajo.

26 «by the reason he erected tents on shore \& those indians came down \& on board \& traded with the English \& here he allso coren'd his ship \& took in provisions wood \& water \&». Hack, 1698. 




Figura 1. Golfo Dulce. Fuente: Hack, 1698.

Hubo otras zonas de Centroamérica que también fueron referidas como posible escala para las navegaciones inglesas. Uno de los mapas de Hack señalaba que la bahía de Mariato se ubicaba cerca de Puebla Nueva, en las costas panameñas, y que se podría ingresar a ella entre las islas de Gobernadores y un punto llamado Filipinas; se indicaba también que convenía hacer escala en ese lugar debido a que contaba con establecimientos de españoles que vendían toda clase de vituallas. ${ }^{27}$ En otro mapa se señalaba que había una bahía llamada English Gulf que también fue bautizada por el capitán Sharp en 1681 ya que ahí, igual que en el caso anterior, hizo escala para conseguir refrescos; incluso en la imagen puede verse que la entrada de la bahía contaba con unas islas que también fueron bautizadas por los ingleses como Duke York Islands (ver figura 2). ${ }^{28}$ 


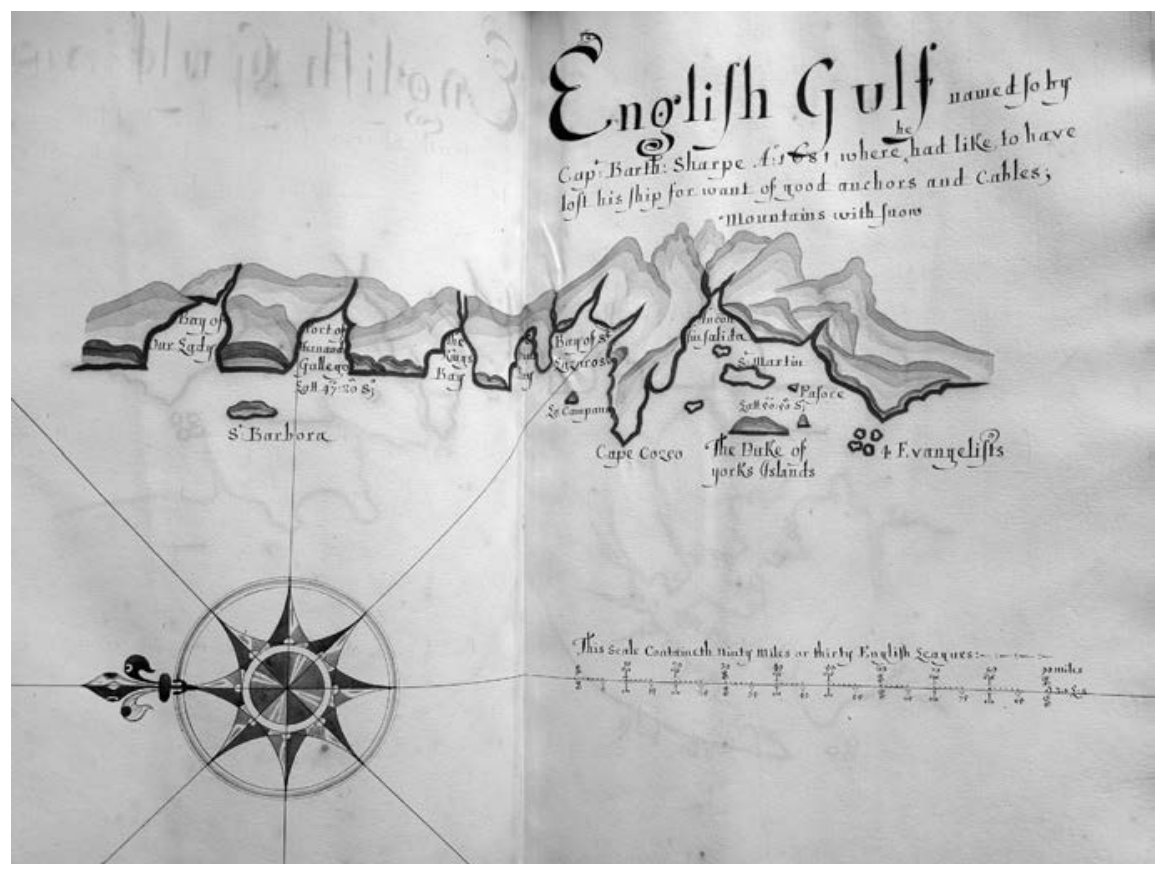

FiguRA 2. English Gulf. Fuente: Hack, 1698.

Lo anterior hace plausible pensar que las representaciones sobre las costas centroamericanas incluidas en el atlas de Hack, además de ser una muestra del avance inglés, evidenciaron su interés en la zona y de ahí los intentos de posicionarse en ella, aunque fuese de forma simbólica rebautizando algunas bahías donde sus navegantes habían transitado.

Estas representaciones no fueron aisladas, sino que surgieron a la par de otras como puede verse con el diario de viaje de William Dampier. Este navegante participó en la expedición que cruzó el Darién, pero tras la muerte del capitán Sawkins él permaneció con el grupo que se dirigió a las costas novohispanas y posteriormente cruzó el Pacífico para finalmente volver a Europa a través del Cabo de la Buena Esperanza. A su regreso a Inglaterra Dampier preparó su libro Nuevo viaje alrededor del mundo (1698) donde describió los lugares por los que su expedición transitó y en su narración la región centroamericana fue incluida. ${ }^{29}$ Mencionó que aunque a lo largo

29 Sobre la estancia de este personaje en Campeche en los campamentos de cortadores de palo de tinte ver Dampier, 2004. Pinzón, 2011. 
de su avanzada por el Darién tuvieron diversas dificultades, también recibieron ayuda de algunos pueblos de indios no sometidos a los españoles. Estos, según Dampier, fueron amables con los ingleses pues usualmente recibían barcos provenientes de Jamaica. Consideró que no estaban sujetos a algún gobierno, pero respetaban la soberanía inglesa y en especial al gobernador de esa isla. Con esos indios incluso consiguieron armas pues ellos las adquirían de los bucaneros a cambio de pescado, tortugas, manatíes o esclavos. Además, estaban asentados desde las costas de Honduras hasta las de Nicaragua, por lo que conocían bien la zona y por ello fueron útiles aliados en el tránsito de los ingleses por el río Santa María, en el golfo de San Michel; inclusive los ayudaron a llegar hasta la isla de la Plata, ya en el Pacífico. ${ }^{30}$ Es decir que estos indios, más allá de proveerles de alimentos, también les dieron informaciones geográficas de gran utilidad para las travesías. El mismo Dampier mencionó que les señalaron unas islas cercanas al río Concepción en las cuales se podía hacer carena con tranquilidad y la prueba de que las habían usado otros bucaneros era que llevaban nombres de sus capitanes, como era el caso de las Sounds Key. ${ }^{31}$

Puede verse que a lo largo de estos avances no se describieron únicamente los contactos amigables con los naturales de la zona ni se hizo referencia solo a los puntos útiles donde se podría hacer escala, sino que también fue importante señalar aquellos lugares que simbólicamente habían sido tomados por los ingleses y renombrados a través de bautismos cartográficos, lo cual continuó realizándose. Además, hay que considerar que estos avances no fueron fortuitos ni mal planeados pues en el caso de las referencias que se hicieron de los pueblos de indios se muestra que los contactos existían y que más bien se incrementaron en el marco de vínculos que se gestaban desde tiempo atrás. Incluso el mismo Dampier explicó que él y sus compañeros lograron interceptar cartas de mercaderes españoles en los que se advertía que los ingleses habían abierto una puerta hacia el Mar del Sur:

Esta puerta que ellos hablaron nosotros concluimos debe ser el pasaje a través del territorio de los indios del Darién, quienes se habían convertido en nuestros amigos y separado de los españoles... Y sobre llamarlos también a pensar en la frecuente invitación que tenían esos indios un poco antes de ese tiempo de pasar a través de su

30 Para este trabajo se usó una edición facsimilar que se basó en la reedición de 1702. Dampier, 1968 [1702], 11-17.

31 Ibidem, 25. 


\section{GUADALUPE PINZÓN RÍOS}

territorio y del de los españoles en el Mar del Sur, que de aquí en adelante comenzamos a tomar esas ideas en serio. ${ }^{32}$

Esta apertura, según Dampier, sentaba las bases a nuevas posibilidades que implicaban extender los tratos ingleses hacia el Mar del Sur e incluso conectarlos con los que se practicaban en Asia. ${ }^{33}$ En su diario narró que al retirarse de las costas novohispanas su expedición se dirigió al oeste y en Mindanao entraron en contacto con el gobernante de la isla, el Rajah Laut, con quien entablaron amistad y hablaron de la posibilidad de protegerlos de los holandeses. Ese contacto, según sugirió Dampier, permitiría a los ingleses extender sus redes marítimas:

Mindanao está convenientemente situada entre las islas de la especiería y las Filipinas y al lado de las tres islas de Meangis solo cerca de veinte leguas desde ahí abundantes con especias y clavo. [...] y a pesar de la gran distancia desde Inglaterra, podremos fácilmente tener suplementos desde ahí, proveyendo naves hacia fines de agosto procedentes del Cabo de Hornos y directamente cruzando el Pacifico para Mindanao o costeando a lo largo de la costa occidental de América tan lejos como fuese necesario, y luego alargar en frente para tener la ventaja de vientos alisios. De esta forma el viaje posiblemente se complete en seis o siete meses, y posiblemente se requieran ocho o nueve para el Cabo de Buena Esperanza. ${ }^{34}$

Aunque la postura de Dampier era demasiado optimista, es posible que narraciones como la suya paulatinamente despertaran el interés de conectar los contactos marítimos del Caribe con los asiáticos, por lo que se fue haciendo cada vez más relevante contar con bases intermedias que lo permitiesen.

32 «This Door the spake of we all concluded must be the Passage over Land through the Country of the Darien, who were a little before this become our Friends, and had lately fallen out with the Spanish... And upon calling also to mind the frequent Invitation we had from those Indians a little before this time, to pass through their Country, and fall upon the Spaniards in the South-Sea, we from henceforward began, to entertain such Thoughts in earnest». Dampier, 1968 [1702], 25.

33 Hay que recordar que los ingleses de la East Indian Company (EIC) desde inicios de siglo XVII comenzaron a llevar a cabo tratos y factorías en plazas como Madrás y hacia 1680 incrementaron sus contactos con el asentamiento portugués de Macao. Sobre el tema ver Souza, 1986, 223. Chaudhuri, $1985,82$.

34 «Mindanao being conveniently situated between the Spice islands and the Philippines, and besides the three islands of Meangis, only about twenty leagues from hence, abound with spice and cloves. [...] and notwithstanding the great distance from England, we might easily have had supplies from thence, providing ships set out the latter end of August, proceeding round Cape Horn, and so directly across the Pacific for Mindanao, or else coasting along the western shore of America as far as was necessary, and then stretching across to have the advantage of the tradewind. By this way the voyage might be accomplished in six or seven months, which would at least require eight or nine by the Cape of Good Hope». En este caso, se recurrió a la compilación de viajes y diarios de navegación hecha por Kerr, 1824, donde se incluye el de Dampier (cita en páginas 278-279). 
Otro personaje que describió la región del Darién fue Lionel Wafer en su libro Un nuevo viaje y descripción del Istmo de América (1699). ${ }^{35}$ También partícipe de la expedición de 1680, durante el trayecto un compañero suyo le disparó accidentalmente en el tobillo, por lo que aunque él mismo se hizo una curación lo mejor posible (ya que era cirujano), no pudo seguir el paso a sus compañeros. Además, los esclavos que los acompañaban escaparon con las medicinas que Wafer llevaba, por lo que sus dolores se intensificaron y tuvo que ser dejado atrás con otros hombres que tampoco pudieron continuar viaje; algunos indígenas amigos les dieron cobijo y a Wafer lo curaron con hierbas, como él mismo mencionó, y después de diversos problemas, los ingleses continuaron viaje y pudieron llegar a las costas atlánticas para regresar a Jamaica. ${ }^{36} \mathrm{Al}$ parecer, esta obra en gran medida se hizo en el marco de otras publicaciones que narraban la expedición de 1680 (como las de Dampier, Ayres, Exquemelin y el atlas de Hack). Pero la de Wafer tenía más noticias de la región del Darién ya que había permanecido ahí por cuatro meses. ${ }^{37}$ Su postura fue menos idealista pues más bien intentó mostrar las características y dificultades que la región presentaba, lo cual no hacía fácil el tránsito de un océano a otro. Explicó que esa parte, la más angosta de América, comúnmente era llamada istmo de Darién, probablemente por el gran río que por ahí corría y llevaba ese nombre. Más allá de ese río las tierras se extendían hacia el noreste hasta la costa del sur donde dejaba de ser llamado istmo. Pero no podía decir si estaba más cercano a Honduras o Nicaragua o bien no más allá del río Chagre o los pueblos de Portobelo y Panamá (ver figura 3)..$^{38}$

Wafer narró también que en el Darién había una cresta que quedaba más cerca del Mar del Norte, aproximadamente a 50 millas de distancia, y desde ahí se podían ver las costas atlánticas e islas adyacentes, aunque el Mar del Sur no se alcanzaba a ver. Esto era porque había mucha distancia hasta él y a simple vista no se le apreciaba, en gran medida debido a las características de la zona ya que había mucha vegetación, valles de considerable extensión y colinas intermedias. Por otro lado, dejó ver que los

35 En su diario explicó que era cirujano y que se trasladó a Jamaica en 1679 por tener un hermano ahí, el cual estaba empleado por Sir Thomas Muddiford; aunque Wafer en principio trabajaría en la misma plantación, pronto prefirió embarcarse en un viaje a Cartagena, en el cual conoció a Dampier. Tomado de A New Collection, 1767, vol. II, 43-44. El personaje también es explicado en el estudio introductorio que hace G. P. Winship a la edición del diario de Wafer (Winship, 1903, 12-20).

36 A New Collection, 1767, vol. II, 51.

37 Winship, 1903, 12-20.

38 A New Collection, 1767, vol. II, 43-87. 
ríos de la zona no eran navegables pues, aunque eran largos, tenían muchas barras y bancos muy pequeños; además en algunas partes el curso del agua era reducido, por lo que poco podían ser de utilidad en las avanzadas. ${ }^{39}$ Así los describió:

El río del Darién es en verdad uno muy grande; pero lo profundo a la entrada no responde a lo ancho de su boca, aunque es profundo más allá: pero desde ahí hasta el Chagre, en todo lo largo de la costa, hay pequeños riachuelos. El río Chagre es bastante considerable; por él hay una larga costa curva, creciendo como hace desde la parte sur y este del istmo, como en distancia desde sus vertientes. Pero en general, la costa norte es variada: generalmente es buena tierra, alzada en colinas; pero hacia el mar hay aquí pantanos, aunque raramente de cerca de media milla de ancho. ${ }^{40}$

Pese a las más realistas descripciones de la zona, Wafer coincidió con Dampier en que esta era habitada en su mayoría por pueblos de indios, mientras que los españoles no tenían presencia ni tampoco control o comercio con ellos. ${ }^{41}$

Para acompañar su relación, y como otros navegantes de su época, Wafer recurrió a Herman Moll para que elaborara un mapa que permitiera visualizar la zona descrita. ${ }^{42}$ Según explican Matthew Restall y Alex Zukas, los mapas de Moll en los que se señaló Centroamérica no se limitaron a representar dicha región sino que más bien mostraron las crecientes avanzadas de las monarquías europeas sobre ella y, en el caso de la inglesa, se señalaron los puntos estratégicos o zonas a evitar como fueron fuertes, poblaciones españolas, puertos, barras de arena, sondas, corrientes, ríos etc. ${ }^{43}$ Por ello el mapa incluido en el diario de Wafer, más allá de contar con los elementos antes mencionados, aportó datos específicos como fueron las

39 Ibidem, 62.

40 «The river of Darien is indeed a very large one; but the depth at the entrance is not answerable to the wideness of its mouth, though it is deep enough farther in: but from thence to Chagre, the whole length of this coast, they are little better than brooks. The river of Chagre is pretty considerable; for it has a long bending coast, rising as it does from the south and east part of the isthmus, and at such a distance from its out-let. But in general, the north-coast [...] is various: generally it is good land, rising in hills; but to the sea there are here and there swamps, yet seldom above half a mile broad». Ibidem, 62-63.

41 Ibidem, 66.

42 Herman Moll fue un conocido cartógrafo de origen alemán que se trasladó a Londres y fue miembro de la Thames School, además de relacionarse con intelectuales de su época como fueron Daniel de Defoe o Jonathan Swift. Sus mapas sobre todo registraron las informaciones aportadas por los navegantes ingleses. Llegó a publicar diversos mapas tanto de forma individual como en trabajos colectivos. Uno de los más relevantes y conocidos fue The World Described. A Map of the West Indies (1715). Ver Restall, 2011.

43 Zukas, 2016. Restall, 2011. 
rutas terrestres por las que los ingleses avanzaron hacia el Mar del Sur y por la que regresaron a las costas del Atlántico, además de mostrar los ríos usados en esas incursiones como fueron el Darién y el Santa María; aunado a lo anterior, también se indicaron las áreas donde había palo de tinte. Por otro lado, en ambas costas se marcaron rutas de navegación que curiosamente fueron más numerosas en el caso de la Bahía de Panamá (figura 3).

Hasta aquí puede verse cómo la región centroamericana fue descrita por los enemigos de España como un espacio viable para continuar sus correrías. Su tránsito era un hecho, sus proyectos continuaron y las avanzadas se modificaron conforme las políticas reales, los conflictos internacionales y las expediciones navales lo permitieron.

\section{Centroamérica: de una zona de tránsito a un botín a capturar}

Las proyecciones sobre la ocupación del Darién fueron retomadas por los escoceses a fines del siglo XVII. A través de una compañía comercial (The Company of Scotland) en 1698 planearon la fundación de la Nueva Caledonia con colonos-plantadores que se asentarían en el lugar. Se consideró que era válido llevar a cabo esta acción debido a que se trataba de una zona de la que los españoles nunca tomaron posesión. Para reafirmar esa postura se consultaron detalladamente los manuscritos de Dampier y Wafer e incluso este último fue llevado a Edimburgo a dar testimonio directo sobre sus experiencias y opiniones de la zona. El proyecto sin embargo no fue aprobado por Inglaterra pues iba en contra de sus propios intereses y ponía en peligro la frágil paz que se mantenía en esos momentos tras la firma del Tratado de Ryswick (1697), ${ }^{44}$ por lo que incluso llegó a prohibirse que desde Jamaica se apoyara a la nueva fundación. No obstante, la expedición se llevó a cabo y mil doscientos colonos se embarcaron con la promesa de nuevas tierras. Pero las difíciles condiciones de la zona, sumadas a las reducidas remesas de víveres, pronto provocaron muertes y deserciones. Además, las presiones diplomáticas españolas, aunadas a los intentos de desalojo por parte de las autoridades locales, llevaron a tomar la decisión de trasladar a los sobrevivientes a Jamaica. ${ }^{45}$ Cabe señalar que el proyecto escocés fue semejante a los

44 La Paz de Ryswick (1697) puso fin al enfrentamiento que la Francia de Luis XIV mantenía con distintos reinos europeos; en el marco de este tratado se aceptó que la parte noroeste de la isla Española pertenecería formalmente a los franceses.

45 Spate, 1983, 169-182. 
procesos de ocupación que se llevaban a cabo en Norteamérica y en algunas islas del Caribe. Aunque al parecer no se tenía el propósito de extender las navegaciones hacia el Pacífico sino más bien fundar una nueva colonia de plantadores, su experiencia mostró las dificultades que la zona representaba. No obstante, el interés de los ingleses por ella no desapareció.

El marco de la guerra de Sucesión fue idóneo para volver a intentar nuevas avanzadas. Hay que recordar que este conflicto, consecuencia de la designación de Felipe de Anjou como heredero de Carlos II, más allá de implicar la posesión del trono hispano también significó la lucha por incursionar en los mercados americanos. Durante este conflicto la corona inglesa ordenó expediciones para hacer corso en las costas americanas; entre ellas pueden mencionarse las travesías de William Dampier de 1701 y posteriormente la de Woodes Rogers de 1708. De la primera Dampier no hizo diario, pero sí lo hicieron algunos de sus tripulantes como puede verse con el Viaje por el Mar del Sur (1707) de William Funnell. En este manuscrito se retomaron algunos puntos mencionados anteriormente sobre las regiones centroamericanas que se relacionaron tanto con las poblaciones como con la geografía del lugar. Por ejemplo, Funnell indicó que los indios de Nicaragua eran amigos de los ingleses pues odiaban a los españoles que les obligaban a pagar parte de sus ganancias, como se veía cuando entregaban la quinta parte de su producción al fraile de la localidad. ${ }^{46}$ Además, la convivencia con esos indios podían ser de utilidad pues algunos de ellos eran buenos pilotos y sabían (pues ya se los habían indicado) dónde había madera, agua, tortugas, peces y hasta ostras de perlas cerca de la bahía de Nicoya. ${ }^{47}$

Por otro lado, Funnell hizo relación de las regiones y tipos de poblaciones por las que transitaron. Por ejemplo, de Sonsonate indicó que era uno de los mejores puertos de las costas de México, que estaba gobernado por un teniente y que contaba con diversidad de casas y pobladores. ${ }^{48}$ Lo relevante del lugar era que se trataba de una zona estratégica pues tenía contactos tanto con el Mar del Norte como a lo largo del Mar del Sur. Así lo mencionó: «Hay algunos tratos desde México con esta plaza y desde Puerto Caballos en el Mar del Norte pero el más importante trato que tiene es desde los grandes imperios de Perú y Chile». ${ }^{49}$

46 Funnell, 1969 [1707], 134-135.

47 Ibidem, 67-72.

48 Ibidem, 115.

49 «There is some trading from Mexico to this place, and from Port Cavallos in the North Sea, bur the most and greatest trade they have is from the two great empires of Peru and Chili». Ibidem,116. 


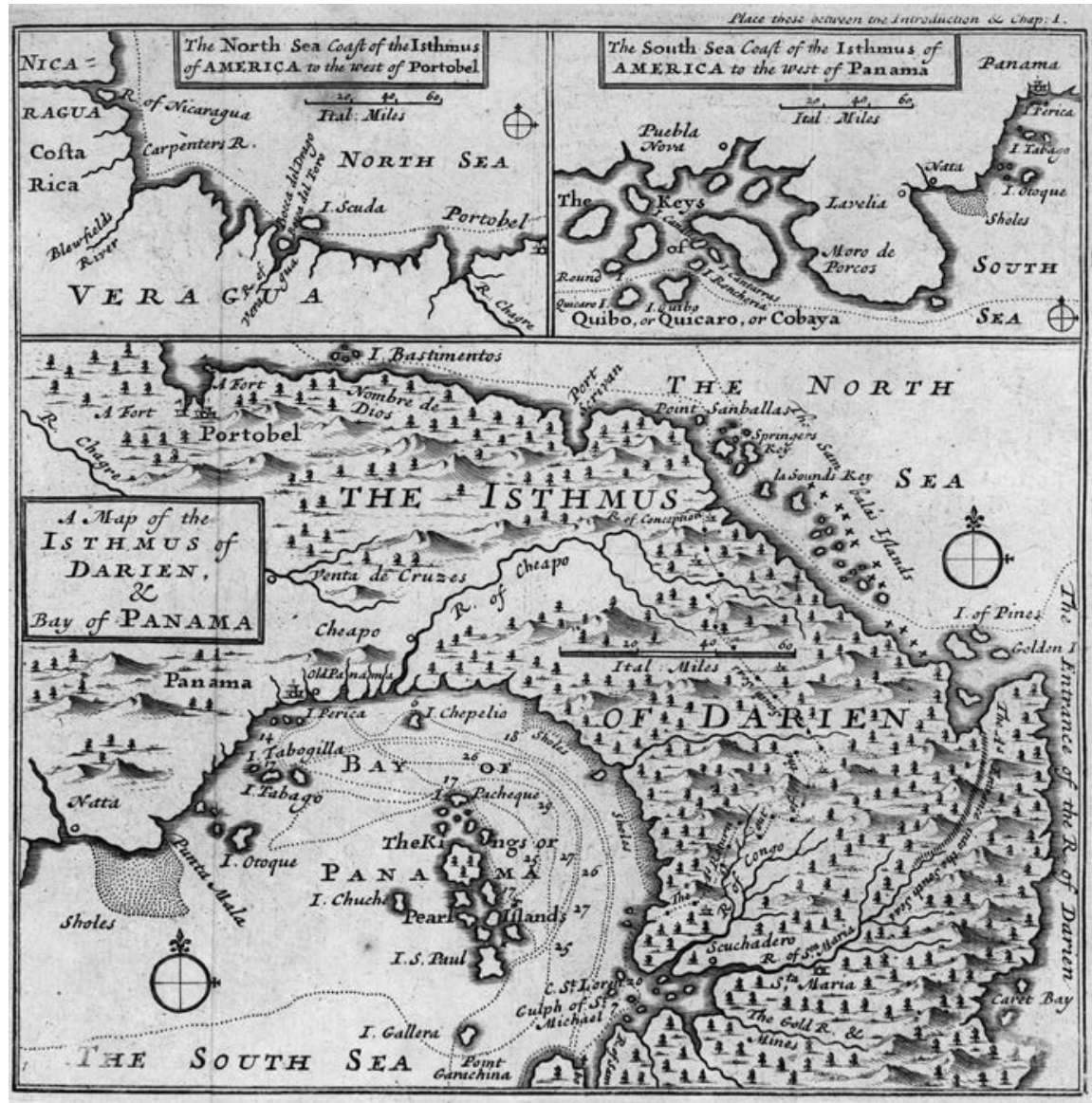

Figura 3. A Map of the Isthmus of Darien \& Bay of Panama. Fuente: Herman Moll, 1699, en Wafer, 1699. ${ }^{50}$

50 Según se explica en la página de la John Carter Brown Library, este mapa se hizo a partir de los informes de Wafer y aparece en su libro A New Voyage and Description of the Isthmus of América, Londres, James Knapton, 1699. La descripción del mapa es: «Map of Panama with Two Inset Maps of the Northern Coast of Panama and the Southern Coast of Panama. Cartographic Elements Includes Scale, Soundings, Sea Banks or Shoals, Compass Rose, some Topographical Details, and the Path to the Pacific from the Atlantic», http://jcb.lunaimaging.com/luna/servlet/detail/JCB MAPS 1 1 1747 103810001:A-Map-of-the-Isthmus-of-Darien, $\&-B$ ?qvq=q:wafer \&mi=0\&trs=7. [Consultado: 17/08/2016]. 
Lo anterior es importante en el sentido de que por un lado se hacía mención sobre la forma de transitar por zonas seguras donde los ingleses no serían capturados por españoles y por el otro se mostraba que había espacios a través de los cuales se podían establecer contactos entre ambos océanos, lo cual sugiere que el proyecto de extender las navegaciones inglesas al Mar del Sur seguía latente. Y nuevamente se intentó mostrar un descontento por parte de las poblaciones locales, la cual podría ser una justificación a usar argumentando que los apoyarían a eliminar el yugo español al que estaban sometidos.

Puede verse que hubo una continuidad en las narraciones inglesas en las que se describieron diversos puntos de Centroamérica como espacios poco vigilados donde podrían establecerse alianzas con los naturales. Y este proceso también se reflejó en la cartografía, pues nuevos mapas que acompañaban a esos diarios retomaron y representaron los lugares que simbólicamente habían sido rebautizados en expediciones previas. Ejemplo de ello es el diario de viaje de Woodes Rogers en el cual se señaló que contenía descripciones de las costas, rutas, bahías, islas, cabos, etc. desde Acapulco hasta Chiloé, información que provenía «del mejor manuscrito español tomado en el Mar del Sur», lo cual hace plausible que se refiriera al atlas de Hack. ${ }^{51} \mathrm{Y}$ uno de los mapas contenidos en el diario señalaba que cerca de la región de Golfo Dulce había un Port English que es probable se retomara del English Gulf señalado en el atlas de Hack (ver figura 4). ${ }^{2}$

No hay que perder de vista que todas estas expediciones generaron alarma entre las autoridades coloniales, lo cual se evidenció con la correspondencia donde se daba aviso sobre la presencia enemiga. Por ejemplo, en 1710 se mandaron misivas desde Madrid donde se informaba de que varios particulares ingleses armaban naves para hacer corso en las costas del Mar del Sur y que las zonas que más debían protegerse eran Perú, Panamá y Guatemala ${ }^{53}$ Es evidente que Centroamérica era la zona más vulnerable ante los avances ingleses y por ello debía reforzarse su defensa.

51 Rogers, 1969 [1712], Apendix (1). Hay que señalar que en la edición de 1685 del atlas de Hack las costas representadas al norte solo llegan hasta Acapulco; es posible que Rogers hiciera referencia a esa versión ya que menciona el libro español de mapas. Ese atlas lleva por título A General Map of this Following Spanish Manuscript Described by William Hack, y puede consultarse en línea en el portal del National Maritime Museum de Greenwich, http://collections.rmg.co.uk/collections/objects/541190. html\#K56ljZliBqosrQTB.99 [Consultado: 17/08/2016].

52 Rogers, 1969 [1712], 144.

53 Aviso sobre presencia enemiga, Madrid, 1710, Archivo General de la Nación, México, Reales Cédulas Originales, vol. 34, 357. 


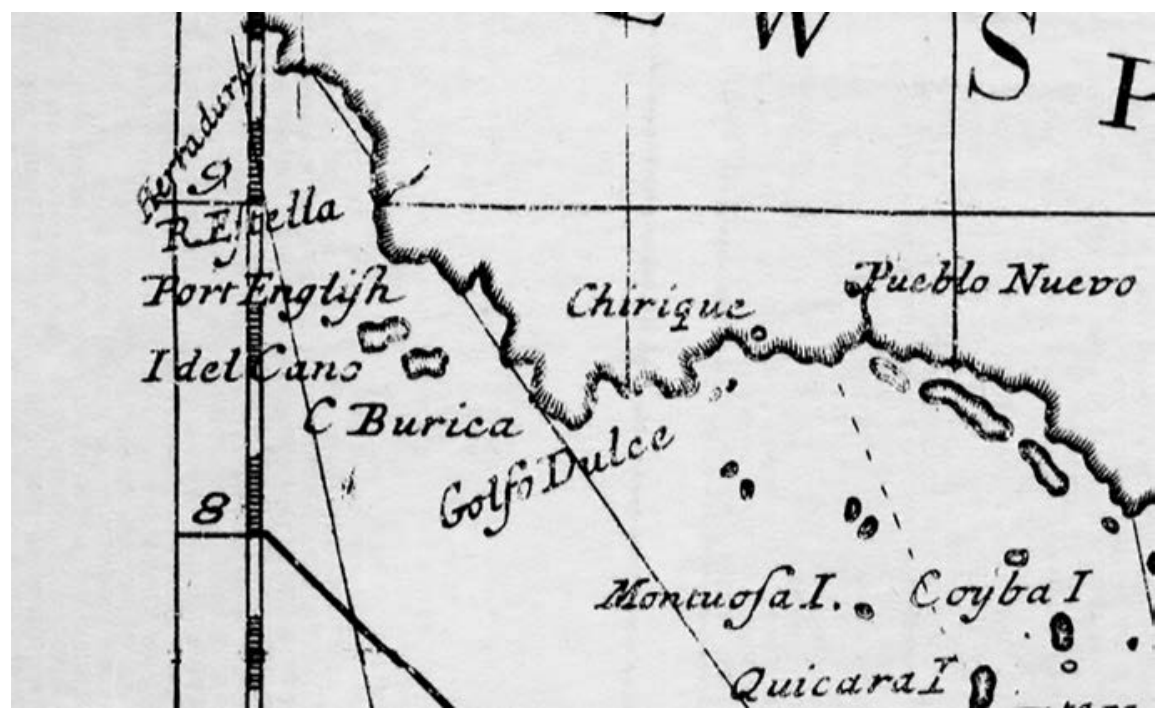

Figura 4. The Pacific or the South Sea (Extracto). Fuente: Rogers, 1969 [1712], 144.

Al finalizar la guerra de Sucesión y firmarse los tratados de Utrecht (1713) los ingleses redujeron sus incursiones por el Pacífico americano pues en gran medida concentraron sus intereses en el comercio que se les había permitido llevar a cabo en Veracruz y Portobelo. ${ }^{54}$ No obstante, continuaron realizándose algunos viajes en el marco de nuevos conflictos, como se vio en 1719 con la expedición de John Clipperton y George Shelvocke luego de iniciar la guerra de la Cuádruple Alianza. ${ }^{55}$ Pero fue tras estallar la guerra del Asiento o de la Oreja de Jenkins (1739-1748) ${ }^{56}$ cuando se lanzó un nuevo ataque que, a diferencia de expediciones previas, se trató de un avance con carácter más oficial en el que la misma monarquía se involucró y encargó a la armada inglesa llevar a cabo formalmente la ocupación de algún territorio centroamericano. El plan fue atacar Portobelo al mismo

54 Souto, 2012.

55 El conflicto se desató luego de que España tomó acciones para recuperar territorios italianos perdidos luego del Tratado de Utrecht y que llevó a que se conformara la Cuádruple Alianza en su contra, la cual fue aprovechada por la asociación de mercaderes ingleses llamada «The Gentleman Adventures» para armar naves con el encargo de atacar las costas del Pacífico americano.

56 Este conflicto estalló debido a las tensiones entre las coronas inglesa y española por el contrabando y corso realizados por sus respectivas embarcaciones en el Caribe. 
tiempo que Panamá. Estos avances estarían a cargo de los oficiales de mar Edward Vernon y George Anson. Se pensó que esto sería posible con la ayuda de las poblaciones locales inconformes con las autoridades españolas de las que se había hecho referencia en los diarios de navegación anteriores. Así que parte de los objetivos de dichas travesías incluían el intento de convencer a los colonos americanos de sublevarse contra los españoles a cambio de recibir la protección de la corona británica así como concesiones como mayor libertad comercial, posibilidad de adquirir manufacturas inglesas a bajo costo, menores tributaciones, tolerancia religiosa, entre otros. ${ }^{57}$ El plan fue descrito en el diario que del viaje de Anson hizo Richard Walter:

\begin{abstract}
A la verdad, en el tiempo que estábamos en la isla de Juan Fernández, había resuelto el jefe de la escuadra tocar en las cercanías de Panamá y procurar allí ponernos en comunicación con la escuadra del almirante Vernon; pues es muy digno de observarse que a nuestra salida de Inglaterra, dejamos en Porstmouth fuerzas considerables para atacar algunas colonias españolas. Suponía Mr. Anson que esto se hubiese así verificado que Puerto-bello estuviese ya ocupado por los ingleses: bajo este supuesto no dudaba que al llegar al Istmo no dejaríamos de adquirir noticias de los nuestros, situados en las costas del otro mar, fuese por los indios que estaban muy mal con los españoles, fuese por algunos espías que podían encontrarse por una buena recompensa. M. Anson se lisonjeaba de poder recibir algún refuerzo por este medio, y nada le parecía más fácil que seguir esta combinación, concertando sus operaciones con los que mandaban nuestras fuerzas en el mar del Norte hasta apoderarse de Panamá. Esta conquista hubiera hecho a la nación inglesa dueña de los tesoros del Perú, o a lo menos de un equivalente por lo que es la Inglaterra hubiera podido juzgar a propósito apropiarse la posesión de alguna de aquellas ricas colonias. ${ }^{58}$
\end{abstract}

Pese a los planes formulados, los objetivos de la expedición cambiaron después de que, gracias a la captura de una nave en las costas de Perú, los prisioneros les informaran que el ataque de Vernon había fallado, por lo que no había condiciones para dirigir su empresa al istmo. Esta noticia llevó a que Anson considerara más pertinente continuar viaje hasta Nueva España para aguardar al galeón de Manila. ${ }^{59}$ Antes pararon en la isla de Quibo, la cual había sido descrita por Dampier y por Rogers. En ese proceso, Anson llegó a criticar que sus relaciones tenían diversos yerros que no le hicieron fácil el arribo. Por ello para llegar a la isla prefirió usar las recomendaciones de un piloto español que iba como prisionero. Sin embargo, el

57 Williams, 2002, 180

58 [Walter], 1833 [1744], 59-60. 45-76.

59 Esto en realidad se logró en las costas filipinas en 1743. Williams, 2002, 180. Pinzón, 2011, 
lugar - como habían descrito los ingleses- resultó ser idóneo para hacer escala por contar con agua dulce, árboles altos, venados en los bosques y tortugas en la costa. ${ }^{60}$

La expedición de Anson al parecer modificó la percepción de los ingleses sobre los litorales americanos y sobre los diarios de navegación elaborados en los anteriores viajes pues se señaló que esas descripciones no eran muy precisas y por tanto no serían de demasiada ayuda en nuevas travesías. Así que, tras regresar a Inglaterra y luego de quedar a cargo del Almirantazgo de la Armada Real Británica (gracias a la captura que hizo de un galeón de Manila), Anson comenzó a llevar a cabo reestructuraciones en las navegaciones inglesas y ordenó mejorar la construcción naval, los registros de las travesías, la forma de enrolar tripulaciones y de tratarlas durante las navegaciones, mejorar los bastimentos a bordo, entre otros puntos. Pero además se modificaron los planes de extender las navegaciones inglesas al Mar del Sur pues en lugar de seguir considerando únicamente a la región centroamericana se prestó atención a la Tierra de Fuego, donde comenzaron a buscarse puntos que pudieran servir de escala en las nuevas empresas planeadas y por ello se volteó la mirada a las islas Malvinas. ${ }^{61}$ Centroamérica siguió siendo región de interés para los ingleses, pero sobre todo en relación con los campamentos de cortadores de palo de tinte, los cuales hacia la segunda parte del siglo XVIII lograron hacerse de Belice como un asentamiento permanente.

\section{Comentario final}

Como ha podido verse, la región de Centroamérica debe ser considerada por sí misma un objetivo claro en los intereses de los ingleses, quienes desde el siglo XVII comenzaron a tomar acciones para su captura. Primero con proyectos o descripciones y posteriormente con planes más concretos, la parte más estrecha del continente americano se vislumbró como una plataforma de ocupación y posteriormente de expansión para los crecientes proyectos navales ingleses que paulatinamente se incrementaron sobre el Mar del Sur. Por ello hay que reiterar que la región centroamericana, más allá de ser una zona de paso, por sí misma significó un botín que se convertiría en la piedra angular de nuevos avances.

60 [Walter], 1833 [1744], 62-63. Sobre el tema Williams, 2002, 180-181.

61 Spate, 1983, 265-267. Williams, 2002, 315-336. 
En ese proceso los ingleses fueron creando un discurso que les permitiera asegurar que sus acciones eran válidas. Esos discursos fueron vertidos en los diarios de viaje y en los mapas de la época. Ambos se convirtieron en instrumentos de propaganda que primero intentaron justificar sus avances y posteriormente intentaron legalizarlos con la toma simbólica que se hizo de algunos puntos, con lo cual se buscó hacer que su presencia fuera más permanente y sus navegaciones más regulares. Los diarios y los mapas, por tanto, no fueron meras descripciones de los avances ingleses, sino instrumentos de poder usados para llevar a cabo sus planes sobre Centroamérica y las costas del Pacífico, los cuales se modificaron conforme los intereses y las políticas internacionales o mercantiles lo fueron requiriendo.

Conocer el caso de las representaciones que los ingleses hicieron sobre Centroamérica es relevante en cuanto a que esto se convirtió en un método usado en distintas zonas, como posteriormente se vio en algunos archipiélagos del Pacífico así como en el noroeste americano, en donde de la misma forma los ingleses intentaron asegurar posesiones y justificar su presencia a partir de sus diarios de viaje y mapas, los cuales volvieron a ser usados como instrumento de poder en esos procesos. Esas fuentes también llegaron a ser consultadas por las autoridades españolas, pues conocerlas les brindó conocimiento de los proyectos y avances de sus enemigos, además de permitirles tomar acciones para repelerlos; esto derivó en reestructuraciones también en el ámbito naval y administrativo del imperio marítimo español que sobre todo se dejó ver a lo largo del siglo XVIII.

Recibido el 20 de enero de 2017

Segunda versión 24 de julio de 2017 Aceptado el 18 de septiembre de 2017

\section{Referencias bibliográficas}

A New Collection of Voyages, Discoveries and Travels: Containing Whatever is worthy of Notice, in Europe, Asia, Africa and America, London, J. Knox, 1767.

Chaudhuri, K. N., Trade and Civilisation in the Indian Ocean. An Economic History from the Rise of Islam to 1750, Cambridge, Cambridge University Press, 1985.

Dampier, William, A New Voyage Round the World [1702], New York, Dover Publications, 1968. 
Dampier, William, Dos viajes a Campeche. Con el facsímil de la edición inglesa de 1705, México, Porrúa, 2004.

Elliott, John H., Imperios del mundo Atlántico. España y Gran Bretaña en América (1492-1830), Madrid, Taurus, 2006.

Exquemelin, Alexandre Olivier, Piratas de América [1678], edic. de Manuel Nogueira Bermejillo, Madrid, Dustin, 2002.

Funnell, William, A Voyage Round the World. Containing an Account of Captain Dampier's Expedition into the South-Seas in the Ship St. George, in the Years 1703 and 1704 [1707], Amsterdam, Nueva York, N. Israel, Da Capo Press, 1969.

García de León, Antonio, Contra viento y marea. Los piratas en el Golfo de México, México, Plaza y Janés, 2004.

Gerhard, Peter, Pirates of the Pacific, 1575-1742, New York, Dover Publications, 2003.

Hack, William, An Accurate Description of all the Harbours Rivers Ports Islands Sands Rocks and Dangers between the Mouth of California and the Straihts of Le Maire in the South Sea of America as allso of Peyps's Islands in the North Sea near to the Magellan Straghts, London, s/e, 1698 [John Carter Brown Library, Codex Z 6 / 3-SIZE].

Haring, Clarence, Los bucaneros de las Indias Occidentales en el siglo XVII, Sevilla, Renacimiento, 2003.

Harley, John Brian, La Nueva naturaleza de los mapas. Ensayos sobre la Historia de la Cartografía, Paul Laxton (comp.), México, Fondo de Cultura Económica, 2005.

Hernández Jaimes, Jesús, «El fruto prohibido. El cacao de Guayaquil y el mercado novohispano, siglos XVI-XVIII», Estudios de Historia Novohispana, 39, México, 2008, 43-79.

Howse, Derek y Trower, Norman J.W. (eds.), A Buccaneer's Atlas. Basil Ringrose's South Sea Waggoner, Berkeley, University of California Press, 1992.

Ita Rubio, Lourdes de, Viajeros isabelinos en la Nueva España, México, Universidad Michoacana de San Nicolás de Hidalgo, FCE, 2001.

Jármy Chapa, Martha de, Un eslabón perdido en la historia. Piratería en el Caribe, siglos XVI y XVII, México, UNAM, 1983.

Kerr, Robert (ed.), A General History and Collection of Voyages and Travels, Arranged in Systematic Order: Forming a Complete History of the Origin and Progress of Navigation, Discovery and Commerce, by Sea and Land, from the Earliest Ages to the Present Time, Edimburg, Printed by James Ballantyne and Company, 1824, vol. 10.

Lynch, John, España bajo los Austrias 1516-1700, Barcelona, Península, 1989 [1970].

MacLeod, Murdo J., Historia socioeconómica de la América Central española, 1520-1720, Guatemala, Editorial Piedra Santa, 1980. 
Maeer, Alistair Simon, The Cartography of Commerce. The Thames School of Nautical Cartography and England's Seventeenth Century Overseas Expansion, $\mathrm{PhD}$ diss., University of Texas at Arlington, 2006.

Martínez de Pisón, Eduardo, Miradas sobre el paisaje, Madrid, Editorial Biblioteca Nueva, 2009.

Meléndez, Mariselle, «The Cultural Production of Space in Colonial Latin America: From Visualizing Difference to the Circulation of Knowledge», in Warf, Barney y Arias, Santa (eds.), The Spatial Turn: Interdisciplinary Perspectives, London, Routledge, 2009, 173-191.

Pérez Mejía, Ángela, «Fronteras de la legalidad: bucaneros en el siglo XVII», Historia y Sociedad, 8, Medellín, 2002, 179-198.

Pérez Brignoli, Héctor, Breve Historia de Centroamérica, México, Alianza Editorial Mexicana, 1986.

Pérez Brignoli, Héctor, Historia General de Centroamérica. 3. De la Ilustración al Liberalismo (1750-1870), Madrid, Sociedad Estatal Quinto Centenario, Ediciones Siruela, 1993.

Pérez Herrero, Pedro, Comercio y mercados en América Latina colonial, Madrid, Mapfre, 1992.

Pinto Soria, Julio César, Historia General de Centroamérica. 2. El régimen colonial (1524-1750), Madrid, Sociedad Estatal Quinto Centenario, Ediciones Siruela, 1993.

Pinzón Ríos, Guadalupe, «Una descripción de las costas del Pacífico novohispano del siglo XVIII», Estudios de Historia Novohispana, 39, México, 2008, 157-182.

Pinzón Ríos, Guadalupe, «William Dampier en el Mar del Sur. Mapas y diarios de viaje ingleses en el reconocimiento del Pacífico novohispano (siglo XVIII)», Fronteras de la Historia, 16-1, Bogotá, 2011, 74-101.

Pinzón Ríos, Guadalupe, «La expedición del capitán Bartholomew Sharp a partir de un mapa (1680-1681)», Antropología. Boletín oficial del INAH, 100, México, 2015, 105-112.

Pinzón Ríos, Guadalupe, «Frontera meridional novohispana o punto de encuentro intervirreinal. El espacio marítimo entre Nueva España y Guatemala a partir de sus contactos navales», en Yuste, Carmen y Pinzón, Guadalupe (coords.), A 500 años del hallazgo del Pacífico (1513-2013). La presencia novohispana en el Mar del Sur, México, UNAM, 2016, 343-362.

Restall, Matthew, «Imperial Rivalries», en Dym, Jordana y Offen, Karl (eds.), Mapping Latin America. A Cartographic Reader, Chicago, Chicago University Press, 2011, 79-82.

Rogers, Woodes, A Cruising Voyage Round the World First to the South Seas Thence to the East Indies and Homeward by the Cape of Good Hope [1712], Amsterdam, Nueva York, Nico Israel, Da Capo Press, 1969.

Schlögel, Karl, En el espacio leemos el tiempo. Sobre Historia de la civilización y Geopolítica, Madrid, Siruela, 2007. 
Suárez, Thomas, Early Mapping of the Pacific. The Epic Story of Seafarers, Adventures and Cartographers Who Mapped the Earth's Greatest Ocean, Singapore, Periplus Editions, 2004.

Souto Mantecón, Matilde, «El comercio inglés en Veracruz: inversiones, ganancias y conflictos generados por el Tratado de Asiento (1713-1717)», en Sánchez Santiró, Ernest y Alves Carrara, Angelo (coords.), Guerra y fiscalidad en la Iberoamérica colonial (siglos XVII-XIX) / Guerra e fiscalidade na Ibero-América colonial (séculos XVII-XIX), Juiz de Fora, México, Editora UFJF, Instituto Mora, 2012, 91-114.

Souza, George Bryan, The Survival of Empire. Portuguese trade and Society in China and the South China Sea, 1630-1754, Cambridge, Cambridge University Press, 1986.

Spate, Oscar H. K., Monopolists and Freebooters. The Pacific since Magellan, Minneapolis, University of Minnesota Press, 1983, vol. II.

Valencia Suárez, María Fernanda, «Visiones inglesas sobre la región maya en el siglo XVI», Península, X, 2, Mérida, 2015, 71-96.

Wafer, Lionel, A New Voyage and Description of the Isthmus of America [1699], edited by George Parker Winship, Cleveland, The Burrows Brothers Company, 1903, https://archive.org/details/anewvoyageandde01wafegoog [Consultado: 17/08/2016].

[Walter, Richard], Viaje alrededor del mundo hecho en los años desde 1740 al 1744 por Jorge Anson, traducido al castellano por Lorenzo Alemany, Madrid, Imprenta de Tomás Jordán, 1833, tomo segundo.

Williams, Glyn, El mejor botín de todos los océanos: la trágica captura de un galeón español en el siglo XVIII, Madrid, Turner, 2002.

Winship, George Parker, «Introduction», en Wafer, Lionel, A New Voyage and Description of the Isthmus of America [1699], Cleveland, The Burrows Brothers Company, 1903, 7-23.

Zukas, Alex, «Port Cities in the Maps of Herman Moll, 1700-1730», World History Connected, 13-1, Illinois, febrero, 2016, s/p., http://worldhistoryconnected. press.illinois.edu/13.1/forum_zukas.html [Consultado: 15/06/2017]. 